\title{
Psychometric Evaluation of the Mental Health Continuum-Short Form (MHC-SF) for Dutch Adolescents
}

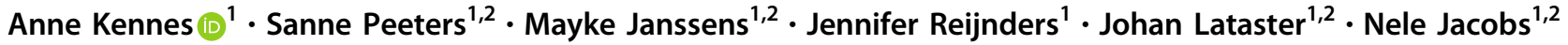

Published online: 20 August 2020

(c) The Author(s) 2020

\begin{abstract}
This study examined the structure, reliability, and convergent validity of the adolescent version of the Mental Health Continuum-Short Form (Dutch MHC-SF-A), a self-report questionnaire for positive mental health assessment. This questionnaire was completed by 459 Dutch adolescents (178 boys and 281 girls) between the ages of 11 and 18 years at baseline and at a 4-week follow-up. Results revealed the 3-factor structure in emotional, psychological, and social wellbeing, a high internal reliability and a moderate test-retest reliability. Findings suggest that mental illness and well-being represent two related but distinct continua of mental health. Fostering adolescents' well-being is important. Promoting positive emotions, creating a supportive and loving parent-adolescent relationship, and a supportive school environment will contribute to this.
\end{abstract}

Keywords Psychometric properties $\cdot$ Positive mental health $\cdot$ Well-being $\cdot$ Adolescent $\cdot$ Mental illness

\section{Highlights}

- Well-being and mental illness are two related but distinct indicators of mental health in Dutch adolescents.

- The MHC-SF-A was shown to be a reliable and valid instrument to measure well-being among Dutch adolescents, measuring emotional, psychological and social well-being.

- Both measures of mental illness and well-being, such as the MHC-SF-A, are needed to map mental health in adolescents and to monitor intervention or therapy outcomes in adolescents.

- The findings suggest that promoting positive emotions, creating a supportive and loving parent-adolescent relationship, and a supportive school environment contribute to adolescents' mental health.

Adolescence is a phase of profound development that involves the transition from childhood to young adulthood. This period is accompanied by various extensive changes in the physical, cognitive, emotional, and social domains (Sisk and Zehr 2005). Adolescence involves the sexual maturation and the physical development of the body, as well as a consolidation of the adolescent's identity and understanding of the self in relation to the social world (Coleman and

Anne Kennes

anneke.kennes@gmail.com

1 Faculty of Psychology and Educational Sciences, Open University of the Netherlands, Heerlen, The Netherlands

2 Department of Psychiatry and Neuropsychology, School for Mental Health and Neuroscience, Maastricht, The Netherlands
Hendry 1990). The focus of social interactions changes and gradually shifts from the family to peers (Brown 2004; Keyes 1998). Parental influence and support decrease, whereas the influence of friends increases (Furman and Buhrmester 1992). While adolescents need to deal with these rapid developmental challenges, they experience an increase in emotional reactivity and negative emotions (Colten and Gore 1991; Hampel and Petermann 2006; Larson and Ham 1993; Nelson et al. 2005) and a decrease in emotional stability (Zimmermann and Iwanski 2014). Successfully meeting these developmental challenges can have a significant and long-lasting impact on adolescents' mental health (McGorry and van Os 2013). Therefore, educational and psychological organizations should foster protective factors that facilitate and teach adolescents how to deal with challenges that occur in this period, so that they can grow up to be resilient adults (McGorry et al. 2007; Waters 
2011). Research has shown that well-being is a protective factor that can contribute to the adolescent's resilience and enables adolescents to deal with everyday stressors and associated negative emotions (Ahern et al. 2006).

Current conceptualizations of well-being (e.g., Keyes 2002, 2005) view well-being as more than the absence of illness. The two-continua model (Keyes 2002, 2005), that can also be applied to adolescents (Greenspoon and Saklofske 2001; Keyes 2006), states that mental illness and mental health represent related but distinct dimensions. The absence of mental illness is neither necessary nor sufficient to ensure well-being. Well-being is best reflected by two longstanding traditions (Ahern et al. 2006): the hedonic tradition and the eudaimonic tradition (Keyes 1998; Waterman 1993). The hedonic tradition entails the affective aspect of well-being which is reflected by emotional well-being (EWB) (Diener et al. 1999; Keyes 2009). According to this tradition, wellbeing is manifested in three components: life satisfaction; the presence of positive emotions; and the absence of negative emotions (Diener et al. 1999; Keyes 2009). The eudaimonic tradition considers optimal psychological functioning both on a personal and social level, conceptualized as, respectively, psychological well-being (PWB) and social-well-being (SWB) (Keyes 2002). The concept of PWB reflects different facets (self-acceptance, personal growth, purpose in life, positive relationships with others, autonomy, and environmental mastery) and focuses on the extent to which persons can realize their potential (Keyes 1998).

PWB correlates with measures of individual functioning (e.g., self-esteem) and the quality of social relationships (Lamers et al. 2011). Good social relationships are considered as a necessary component of PWB (Keyes 1998). SWB additionally, reflects facets of optimal functioning in community life (social integration, social contribution, social coherence, social actualization, and social acceptance) and focuses on the extent to which individuals feel accepted by their communities and can acknowledge their contribution to society (Keyes 1998; Waterman 1993). SWB covers wider social relationships than solely close friends and family relationships (Keyes 1998) and correlates with measurements of involvement in society (Lamers et al. 2011). The important role of well-being as a resilience factor in adolescence underscores the need to examine it more closely. Whereas global life satisfaction and EWB have been shown to decline with the onset and progression of adolescence (Gloldbeck et al. 2007; Gonzalez-Carrasco et al. 2017; Hong Chui and Wong 2016; Liu et al. 2015; Uusitalo-Malmivaara 2014), it remains unclear whether this decline can also be found for PWB and SWB. Moreover, only a few studies (Guo et al. 2015; Lim 2014) have comprehensively assessed adolescents' well-being across the emotional, psychological, and social domains.
The Mental Health Continuum-Short Form (MHC-SF; Keyes and Grzywacz 2005) was specifically developed to measure EWB, PWB, and SWB. This self-report questionnaire, consisting of 14 items, has been investigated and has shown good internal consistency and convergent validity as well as confirming the two-continua model of mental health and illness (Keyes 2002, 2005) in adult samples from the Netherlands, South Africa, Italy and the U.S. (Keyes et al. 2008; Lamers et al. 2011; Petrillo et al. 2015; Salama-Younes and Ismaill 2011) as well as in adolescent samples from Asian countries (Guo et al. 2015; Lim 2014). However, for Dutch-speaking adolescents, a reliable and valid instrument to assess well-being in adolescence is still lacking. As the field of practice focuses increasingly on well-being among adolescents, an instrument adapted to this age group is needed to validly and reliably capture variance in well-being (Keyes 2002, 2005).

In order to construct and evaluate such an instrument, this study aimed to adapt the MHC-SF to adolescents, to investigate the factor structure of the adapted MHC-SF (hereafter referred to as MHC-SF-A), and to analyze its psychometric properties. In addition, this study aimed to confirm the two-continua model in a sample of Dutch adolescents. In accordance with previous studies, firstly, it is expected to confirm the three-factor structure of EWB, PWB, and SWB (Guo et al. 2015; Keyes 2002, 2005; Lim 2014). Furthermore, considering earlier findings in adult and adolescent samples, it is hypothesized that the three subscales of the MHC-SF-A have high internal reliability, moderate reliability over time and larger test-retest reliability for the direct paths (e.g., EWB at baseline predicting EWB at follow-up) than for the cross-over paths (e.g., EWB at baseline predicting SWB at follow-up) (Guo et al. 2015; Lamers et al. 2011; Lim 2014). Secondly, it is hypothesized that the present study confirms the convergent validity of the MHC-SF-A, correlating the three subscales EWB, PWB, and SWB with corresponding measures. It is expected that EWB correlates with aspects of EWB, such as measures of positive emotions and negative emotions; PWB correlates with measurements of individual functioning (e.g., self-esteem) and positive relationships with parents and peers and SWB correlates with measurements of involvement in society, such as belonging to groups and being involved in school activities, that represent opportunities for adolescents to explore different identities and social roles and enhance their levels of sense of community and SWB (Salama-Younes and Ismail 2011). Lastly, it is expected that SWB correlates with adolescents' school experiences. Thirdly, it is hypothesized that the twocontinua model is confirmed in a sample of Dutch adolescents: demonstrating that mental health and mental illness are two related, but distinct, latent factors with low to moderate negative correlations. 


\section{Method}

\section{Participants}

At baseline, 459 Dutch adolescents (178 boys and 281 girls) between the ages of 11 and 18 years participated. At followup, 283 participants $(61.7 \%$; hereafter referred to as completers $)$ of the initial sample completed the survey $\left(M_{\text {age }}=\right.$ $14.34 S D_{\text {age }}=1.97$, range $\left._{\text {age }}=11-18\right)$. There were 108 boys and 175 girls at follow-up. Compared to participants who only completed the baseline survey (hereafter referred to as dropouts), the completers had significantly higher education levels, were significantly younger and reported a significantly higher score on the three scales of the MHCSF-A (Table 1). No significant differences were observed in the cultural background between dropouts and completers.

\section{Procedure}

The present study was approved by the local research ethics committee of the Open University and was carried out in accordance with the Code of Ethics of the World Medical Association (Declaration of Helsinki) for medical

Table 1 Sample characteristics of dropouts/completers and the difference between the two samples

\begin{tabular}{|c|c|c|c|}
\hline & $\begin{array}{l}\text { Dropouts } \\
(n=176)\end{array}$ & $\begin{array}{l}\text { Completers } \\
(n=283)\end{array}$ & $\begin{array}{l}\text { Completers versus } \\
\text { dropouts }\end{array}$ \\
\hline Age M (SD) & $15.32(1.87)$ & 14.34 (1.97) & $t(457)=-5.26^{*}$ \\
\hline \multicolumn{4}{|l|}{ Gender } \\
\hline Boys (\%) & 39.4 & 38.2 & \multirow[t]{2}{*}{$\chi^{2}(1)=0.143$} \\
\hline Girls (\%) & 60.6 & 61.8 & \\
\hline \multicolumn{4}{|l|}{ Country of birth } \\
\hline $\begin{array}{l}\text { Born in the } \\
\text { Netherlands (\%) }\end{array}$ & 92.8 & 95.4 & \multirow[t]{2}{*}{$\chi^{2}(1)=1.197$} \\
\hline Born abroad (\%) & 7.2 & 4.6 & \\
\hline \multicolumn{4}{|l|}{ Living-situation } \\
\hline $\begin{array}{l}\text { Living with both } \\
\text { parents }(\%)\end{array}$ & 72.9 & 77.4 & \multirow[t]{2}{*}{$\chi^{2}(1)=0.271$} \\
\hline Other $(\%)$ & 27.1 & 22.6 & \\
\hline \multicolumn{4}{|l|}{ Level of education } \\
\hline $\operatorname{High}^{\mathrm{a}}(\%)$ & 39.8 & 54.1 & \multirow[t]{2}{*}{$\chi^{2}(1)=10.327^{*}$} \\
\hline Low $^{\mathrm{b}}(\%)$ & 60.2 & 45.9 & \\
\hline \multicolumn{4}{|l|}{ Well-being } \\
\hline EWB M (SD) & $3.55(0.98)$ & $3.87(0.85)$ & $t(326)=3.48^{*}$ \\
\hline PWB M (SD) & $3.38(0.95)$ & $3.63(0.84)$ & $t(330)=2.86^{*}$ \\
\hline SWB M (SD) & $2.87(0.95)$ & $3.11(0.85)$ & $t(330)=2.73^{*}$ \\
\hline
\end{tabular}

$E W B$ emotional well-being, $P W B$ psychological well-being, $S W B$ social well-being, $M$ Mean, $S D$ standard deviation

$* p<0.01$

${ }^{a}$ Higher than vocational education

${ }^{\text {b}}$ Vocational education research involving humans (World Medical Association 2013). Data was collected through convenience sampling. Dutch adolescents, primarily recruited, by undergraduate psychology students, through six secondary schools spread over the Netherlands were asked to complete an online questionnaire at baseline (MHC-SF-A, Kidscreen52, The Strengths and Difficulties Questionnaire, selfworth scale of the Harter's Social Perception Profile for Children and the FEEL-KJ) and at a 4-week follow-up (MHC-SF-A). Prior to participation, informed consent was obtained from all adolescent participants. For adolescent participants younger than 16 years old, informed consent was additionally obtained from their parents. In the informed consent, ethical and privacy issues were covered. Confidentiality, as well as anonymity, was ensured. Inclusion criteria were: Dutch-speaking and between the ages of 11 and 18 years old.

\section{Measures}

\section{Mental Health Continuum-Short Form for Adolescents (MHC-SF-A)}

The MHC-SF (Keyes et al. 2008) is a self-report questionnaire, measuring the emotional, psychological, and social components of well-being. The MHC-SF was translated and validated into Dutch for an adult target group by Lamers et al. (2011). This questionnaire consists of 14 items representing various feelings of well-being. EWB was calculated by the sum score of items $(1,2,3)$. SWB was calculated by the sum score of items (4-8). The PWB was calculated by the sum score of items (9-14). Respondents rated the frequency of every feeling in the past month on a 6-point Likert scale. An example of an item of the EWBscale is: "During the past month, how often did you feel happy". An example of an item of the PWB-scale is: “... you had warm and trusting relationships with others". An example of an item of the SWB-scale is: "...you belonged to a community (like a social group, or your neighborhood)". Internal reliability of this adult version is high (Cronbach's $\alpha$ of 0.74 to 0.89 ) and the test-retest reliability of the questionnaire varies from 0.49 to 0.65 (Lamers et al. 2011). The Dutch adult version of the MHC-SF (Lamers et al. 2011), was adapted by a psychologist to a target group of Dutch adolescents. Three 12-year-old adolescents were asked to evaluate all items of the Dutch adult version. The questionnaire items were revised upon reviewing the results of this preliminary pilot test. The items written in the courtesy form were replaced by the same items in the familiar form. Incomprehensible and difficult words in the items were adapted accordingly, resulting in the Mental Health Continuum-Short form for Adolescents (MHC-SF- 
A).The psychometric properties of the MHC-SF-A are discussed in the results section.

\section{Kidscreen-52}

Kidscreen-52 (Ravens-Sieberer et al. 2008) is a self-report questionnaire for preadolescents and adolescents aged 8-18 years old, measuring ten different dimensions of their perceptions of their health and well-being. The questionnaire consists of 52 items measuring 10 dimensions: physical well-being, psychological well-being, moods and emotions, self-perception, autonomy, relations with parents and home life, social support and peers, school environment, social acceptance, and financial resources. In this study the adolescent version was used. The items used a 5-point Likert scale to assess either the frequency of an attitude (never-seldom-sometimes-oftenalways) or certain behaviors/feelings. The total score for a scale was calculated using the sum score of the items belonging to that scale. An example of an item is: "Remember the past week. Have you had fun?". The test-retest reliability of the questionnaire varies between 0.56 to 0.77 . Cronbach's $\alpha$ (internal consistency) ranges from 0.76 to 0.89 (Ravens-Sieberer et al. 2008).

\section{Global Self-worth}

Global self-worth was assessed with a subscale of the Dutch version of the Harter's Social Perception Profile for Children (SPPC) (Treffers et al. 2002). This subscale consists of five items. Two complementary propositions (negative versus positive) were offered simultaneously for each item. Each statement describes a group of young people (for example: "Some young people are quite satisfied with themselves" versus "Other young people feel that they are not so satisfied with themselves"). First, the respondents chose the group which they fit the best. Afterwards, they indicated whether the description was somewhat true or very true. Each item received a score between one and four. The score on self-worth was determined by the sum score of the five items. The value of Cronbach's $\alpha$ of the SPPC is greater than 0.70 for all scales, indicating an acceptable internal consistency (Treffers et al. 2002). A Dutch study has provided evidence for a high test-retest reliability (Pearson correlations of 0.67 to 0.87 ) and a good validity (Treffers et al. 2002).

\section{The Strengths and Difficulties Questionnaire (SDQ)}

SDQ (Muris et al. 2003) is a brief screening measure to identify the behavioral and emotional problems of adolescents. In this study the Dutch self-report version (Muris et al. 2003) was used. SDQ consists of 25 items measuring five scales, with four scales focusing on difficulties relating to behavior, emotional functioning, hyperactivity/ inattention, interaction with peers, and one scale focusing on the strength of prosocial behavior. Each subscale consists of five items. There are three response categories (not true $=0$, a little true $=1$, certainly true $=2$ ) resulting in a maximum score of 10 for each of the subscales, which are indicative of the magnitude of the problems on each domain. A total difficulty score was obtained by making the sum of all items of the four scales focusing on difficulties. This score indicates to what extent the adolescent suffers from socio-emotional problems. For each subscale, with the exception of prosocial behavior, higher scores reflect more problems. The internal consistency is acceptable for both the total score (Cronbach's $\alpha$ of 0.70) and for the subscales (Cronbach's $\alpha$ between 0.60 and 0.65 ) (Muris et al. 2003). Research has found a satisfactory test-retest reliability of the various scales. All subscales, except prosocial behavior (0.59), have correlation coefficients of 0.70 or more (Muris et al. 2003). An example of an item is: "I worry a lot".

\section{Adaptive and Maladaptive Emotion Regulation Strategies}

The Dutch version of the FEEL-KJ (Cracco et al. 2015) is a 90 -item self-report questionnaire to assess 15 emotion regulation strategies of adolescents in response to anxiety, sadness, and anger. For each of the emotions, an emotion regulation strategy is measured by two items. The emotion regulation strategies are subdivided into three categories: adaptive strategies (acceptance, problem-oriented action, cognitive problem solving, distraction, neglect, revaluation, and put into good humor), maladaptive strategies (giving up, aggressive action, withdrawal, self-devaluation, and perseveration) and external regulatory strategies. The items were scored on the basis of a five-point scale (from $1=$ almost never to $5=$ almost always). The total score for the adaptive and maladaptive strategies were calculated using the sum score of the items belonging to that secondary scale. An example of an item is "When I am sad, I think back to cheerful things". The scales of the FEEL-KJ are reliable with a Cronbach's $\alpha$ of 0.87 (adaptive strategies) and 0.76 (maladaptive strategies) (Cracco et al. 2015). The internal consistency and conceptual validity are good (Cracco et al. 2015).

\section{Data Analysis}

The data was analyzed using SPSS 25.0 and R 3.4.3 (R Core Team 2019). Descriptive statistics of frequencies, means, and standard deviations were calculated for all subscales. To confirm the three-factor model as proposed by 
Keyes (2002, 2005), confirmatory factor analyses (CFA), using the MHC-SF-A subscales at baseline, were performed. Three conceptional models were evaluated: a single-factor model with a unique measure of mental health, a two-factor model with one factor representing EWB and one factor representing PWB and SWB and a three-factor model (EWB, PWB, SWB) based on the hypothesis of this study. Maximum likelihood was used as estimation method. To assess the goodness of fit, the chi-square $\left(\chi^{2}\right)$, comparative-fit-index (CFI), Tucker-Lewis index (TLI) and standardized root-mean-square residual (SRMR), Root Mean Square Error of Approximation (RMSEA), Akaike's information criterion (AIC) and Bayesian information criterion (BIC) were calculated. CFI and TLI values above 0.90 (Kline 1998; Tabachnick and Fidell 2001), $\chi^{2} / d f$ below 5 (Arbuckle 2016), RMSEA between 0.05 and 0.1 (Arbuckle 2016) and SRMR values below 0.09 (Hu and Bentler 1999) were considered to indicate an adequately parameterized model. The structure with the lowest AIC and BIC value would indicate a better fit (Akaike 1974; Stone 1979). Internal consistency was determined by Cronbach's alpha coefficients. Values above 0.70 were considered as acceptable, and values above 0.80 as high (Kline 1998; Nunnally and Berstein 1995). The stability of the three subscales was examined by performing a regression analysis. For each subscale, a regression analysis with that subscale at follow-up as dependent variable and the three subscales at baseline as independent variables was performed. Only for this analysis, the sample was restricted to the completers $(N=283)$.

Using baseline data, bivariate and partial correlations of the subscales of the MHC-SF-A with correspondent validation measures of well-being and psychopathology were performed to test for convergent validity. The partial correlations were controlled for the other MHC-SF-A subscales. Correlations around 0.20 were considered to be low, and around 0.50 to be moderately high (Nunnally and Berstein 1995).

In addition, in order to obtain evidence for the twocontinua model, an exploratory and a confirmatory analysis were performed using the MHC-SF-A and SDQ subscales at baseline. To assess the sampling adequacy, a KaiserMeyer-Olkin (KMO) measure was conducted. A KMO measure was considered good when the value was between 0.7 and 0.8, and excellent when between 0.8 and 0.9 (Hutcheson and Sofroniou 1999). First, an exploratory factor analysis (EFA) at baseline was performed to reveal the number of factors with an eigenvalue greater than 1 . Afterwards, to confirm the two-continua model, a confirmatory factor analyses (CFA) using maximum-likelihood estimation was performed. Two conceptual models were evaluated: a single-factor model with a unique measure of mental health where the absence of mental illness equaled the presence of mental health, and the two-continua model. To assess the goodness of fit, the chi-square $\left(\chi^{2}\right)$, comparative-fit index (CFI) and standardized root-meansquare residual (SRMR), Root Mean Square Error of Approximation (RMSEA), Akaike's information criterion (AIC) and Bayesian information criterion (BIC) were calculated. In all analyses, a significance level of 0.01 was applied, because of a large sample size.

\section{Results}

Table 2 and Table 3 summarize the descriptive statistics of the main study variables.

\section{Structural Validity}

Table 4 shows that the three-factor structure as proposed by Keyes $(2002,2005)$ fitted the data better than the one-factor and the two-factor models. The three-factor structure had the lowest AIC and BIC values, the highest CFI and TLI values and was the only structure with a CFI above 0.9. None of the models indicated a poor fit for SRMR and $\chi^{2}$. Table 5 displays the standardized factor loadings for the three-factor model. In order to analyze internal consistency of the MHC-SF-A, the correlation between the score of the items and the corresponding scale were calculated. The factor loadings exceeded the minimum acceptable value of 0.30 (Nunnally and Bernstein 1995). The three factors EWB, PWB and SWB were interrelated. The highest correlation was between EWB and PWB with a magnitude of 0.872 The lowest correlation was between EWB and SWB of 0.745 . The total variance explained by the factors (EWB, PWB, and SWB) is $59.17 \%$

Table 2 Mean, SD of the main study variables of the sample at baseline $(n=459)$

\begin{tabular}{lrl}
\hline & $M$ & SD \\
\hline EWB of MHC-SF-A & 3.75 & 0.91 \\
PWB of MHC-SF-A & 3.54 & 0.89 \\
SWB of MHC-SF-A & 3.02 & 0.89 \\
Total well-being of MHC-SF-A & 3.40 & 0.80 \\
"Feelings" of Kidscreen-52 & 23.93 & 4.37 \\
"Self-esteem" of SPPC & 2.71 & 0.76 \\
"School environment" of kidscreen-52 & 21.97 & 4.27 \\
"Social Support and Peers" of kidscreen-52 & 23.78 & 3.94 \\
"Parent relations" of kidscreen-52 & 25.85 & 3.96 \\
Total score of SDQ & 10.92 & 5.54 \\
\hline
\end{tabular}

$E W B$ emotional well-being, $P W B$ psychological well-being, $S W B$ social well-being, $M H C-S F-A$ Mental Health Continuum-Short form for Adolescents, $S D Q$ The Strengths and Difficulties Questionnaire 
Table 3 Correlations between the main validation measures of the sample at baseline $(n=459)$

\begin{tabular}{lllllll}
\hline & 1 & 2 & 3 & 4 & 5 & 6 \\
\hline 1. "Feelings" of Kidscreen-52 & 1 & & & & & \\
2. "Self-esteem" of SPPC & $0.473^{*}$ & 1 & & & & \\
3. "School environment" of kidscreen-52 & $0.605^{*}$ & $0.329^{*}$ & 1 & & & \\
4. "Social Support and Peers" of kidscreen-52 & $0.542^{*}$ & $0.260^{*}$ & $0.404^{*}$ & 1 & & \\
5. "Parent relations" of kidscreen-52 & $0.583^{*}$ & $0.329^{*}$ & $0.488^{*}$ & $0.435^{*}$ & 1 & \\
6. Total score of SDQ & $-0.566^{*}$ & $-0.373^{*}$ & $-0.525^{*}$ & $-0.328^{*}$ & $-0.440^{*}$ & 1 \\
\hline
\end{tabular}

$E W B$ emotional well-being, $P W B$ psychological well-being, $S W B$ social well-being, $M H C$-SF-A Mental Health Continuum-Short form for Adolescents

$* p<0.01$

Table 4 CFA models of the latent structure of the MHC-SF-A

\begin{tabular}{llll}
\hline & One-factor model & Two-factor model & $\begin{array}{l}\text { Three- } \\
\text { factor model }\end{array}$ \\
\hline$\chi^{2}(\mathrm{df})$ & $434.28(77)^{*}$ & $364.38(76)^{*}$ & $322.93(74)^{*}$ \\
CFI & 0.860 & 0.887 & 0.903 \\
TLI & 0.835 & 0.865 & 0.880 \\
RMSEA & 0.101 & 0.091 & 0.086 \\
SRMR & 0.065 & 0.060 & 0.061 \\
AIC & 18508 & 18441 & 18402 \\
BIC & 18623 & 18560 & 18530
\end{tabular}

$\overline{\chi^{2} \text { Satorra-Bentler scaled chi-square, } d f \text { degree of freedom, } C F I}$ comparative-fit index, TLI Tucker-Lewis index, RMSEA root mean square error of approximation, SRMR standardized root mean square residual, $C F A$ confirmatory factor analysis, $M H C-S F-A$ Mental Health Continuum-Short form for Adolescents, AIC Akaike's information criterion, $B I C$ Bayesian information criterion

$* p<0.01$

\section{Reliability}

The subscales of the MHC-SF-A yielded a high internal consistency. The EWB subscale had the highest internal consistency $(\alpha=0.84)$, the SWB subscale had the lowest $(\alpha=0.70)$. This is in line with our expectations.

The results of the crossover path analysis showed that each subscale consistently predicted the same subscale at follow-up (Table 6). The prospective association for PWB was largest, having a magnitude of 0.530. EWB had the lowest, having a magnitude of 0.445 . The regression coefficients associated with direct paths (e.g., EWB at baseline predicting EWB at follow-up) were significant and moderate, suggesting that the MHC-SF-A is sufficiently stable over time, but also sensitive enough to change. Focusing on the cross-over paths (e.g., EWB at baseline predicting SWB at follow-up), each subscale was also positively related with the other two subscales at follow-up. For example, SWB predicted also EWB and PWB but with low magnitudes between 0.148 and 0.226 . Comparing to the direct paths, cross-over paths had lower regression coefficients. These results are in conformity with the expectations of this study.
Table 5 Standardized factor loadings for the three-factor model of MHC-SF-A

\begin{tabular}{llll}
\hline Theoretical dimension & EWB & PWB & SWB \\
\hline Emotional well-being & 1 & 0.872 & 0.745 \\
01. Happiness & 0.829 & & \\
02. Interest & 0.813 & & \\
03. Life satisfaction & 0.750 & & \\
Psychological well-being & 0.872 & 1 & 0.829 \\
09. Self-acceptance & & 0.729 & \\
10. Mastery & & 0.595 & \\
11. Positive relations & & 0.652 & \\
12. Personal growth & & 0.475 & \\
13. Autonomy & & 0.619 & \\
14. Purpose in life & & 0.791 & \\
Social well-being & 0.745 & 0.829 & 1 \\
04. Soc. contribution & & & 0.559 \\
05. Soc. integration & & & 0.427 \\
06. Soc. actualization & & & 0.656 \\
07. Soc. acceptance & & & 0.667 \\
08. Soc. coherence & & & 0.584 \\
\hline
\end{tabular}

$E W B$ emotional well-being, $P W B$ psychological well-being, $S W B$ for Adolescents

\section{Convergent Validity}

Table 7 shows the bivariate and partial correlations of the MHC-SF-A subscales with the validation measures. All bivariate correlations were statistically significant. Only significant partial correlations are mentioned. All significant partial correlations were low with a range between 0.119 and 0.399. Measures that focus on aspects of EWB, such as positive and negative emotions, showed the strongest partial correlations with the subscale EWB and also significant partial correlations with PWB. Measurements of individual functioning (e.g., self-esteem) and adolescents' perceptions of the nature of their relationships with parents and peers showed the strongest significant partial and bivariate correlations with PWB. The subscale "school environment" social well-being, MHC-SF-A Mental Health Continuum-Short form 
showed a significant partial and bivariate correlation with the three subscales. These results are in conformity with the expectations of this study.

\section{Discriminant Validity: Two-Continua Model}

The EFA testing the two-continua model revealed two factors with an eigenvalue greater than 1 . The KMO index was 0.756 , indicating that the correlation matrix was adequate. These two factors explained $65.89 \%$ of the variance. Table 8 shows the factor loading of the subscales of the MHC-SF-A and the SDQ with the two factors mental health and mental illness. All subscales had the highest loading on the intended factor. Well-being and mental illness had a negative correlation of -0.29 . Consecutively, a CFA was performed. Table 9 shows that the two-continua model was

Table 6 Regression analysis of the MHC-SF-A subscales as predictors of MHC-SF-A at follow-up

\begin{tabular}{lll}
\hline Dependent variable & Predictor & $B$ \\
\hline EWB & EWB & $\mathbf{0 . 4 4 5 *}$ \\
& PWB & $0.387^{*}$ \\
& SWB & 0.003 \\
PWB & EWB & $0.267^{*}$ \\
& PWB & $\mathbf{0 . 5 3} *$ \\
SWB & SWB & 0.058 \\
& EWB & $0.148^{*}$ \\
& PWB & $0.226^{*}$ \\
& SWB & $\mathbf{0 . 4 7 2}$ \\
\hline
\end{tabular}

Bold: values indicate magnitude for direct paths

$E W B$ emotional well-being, $P W B$ psychological well-being, $S W B$ social well-being, MHC-SF-A Mental Health Continuum-Short form for Adolescents

$* p<0.01$ the model with the best fit. The two-continua model had the lowest AIC and BIC values, the highest CFI and TLI and a SRMR value below 0.9 .

\section{Discussion}

The present study investigated the factor structure, evaluated the psychometric properties of the MHC-SF-A and tested for the presence of two-continua of mental health, in a sample of Dutch adolescents between the ages of 11 and 18 years old. Evidence of construct validity was found for a three-factor structure as proposed by Keyes $(2002,2005)$. The data confirmed the theoretically based classification of the 14 items of the MHC-SF-A in the three subscales: EWB, PWB, and SWB. In previous studies, the same structure has been found in adult samples from the Netherlands, South Africa, Italy and the USA (Keyes et al. 2008; Lamers et al. 2011; Salama-Younes, and Ismail 2011; Petrillo et al. 2015) and adolescent samples from different

Table 8 MHC-SF-A and SDQ: Standardized factor loadings from EFA with two-factor oblimin rotation

\begin{tabular}{lcc}
\hline Dependent variable & Mental health & Mental illness \\
\hline MHC-SF-A & & \\
Emotional well-being & $\mathbf{0 . 8 5 8}$ & -0.282 \\
Psychological well-being & $\mathbf{0 . 8 9 7}$ & -0.168 \\
Social well-being & $\mathbf{0 . 8 5 9}$ & -0.292 \\
SDQ & & \\
Conduct problems & -0.039 & $\mathbf{0 . 8 6 0}$ \\
Hyperactivity/inattention & -0.354 & $\mathbf{0 . 6 8 2}$ \\
Peer relationship problems & -0.455 & $\mathbf{0 . 5 3 4}$
\end{tabular}

MHC-SF-A Mental Health Continuum-Short form for Adolescents, $S D Q$ The Strengths and Difficulties Questionnaire

Table 7 MHC-SF-A

\begin{tabular}{|c|c|c|c|c|}
\hline & EWB & PWB & SWB & Total MHC-SF-A \\
\hline "Feelings" of Kidscreen-52 & $0.679 * / \mathbf{0 . 3 9 9} *$ & $0.643 / \mathbf{0 . 2 8 1} *$ & $0.503 *$ & $0.676^{*}$ \\
\hline "Moods" of Kidscreen-52 & $-0.575 * /-\mathbf{0 . 3 3 7 *}$ & $-0.547 * /-0.262 *$ & $-0.362 *$ & $-0.548^{*}$ \\
\hline "Self-esteem" of SPPC & $0.305^{*}$ & $0.326 * / \mathbf{0 . 2 8 1} *$ & $0.220 *$ & $0.320 *$ \\
\hline "School environment" of kidscreen-52 & $0.486^{*} / \mathbf{0 . 1 7 5} *$ & $0.502 * / \mathbf{0 . 1 8 7} *$ & $0.450 * / \mathbf{0 . 1 2 8} *$ & $0.540 *$ \\
\hline "Social Support and Peers" of kidscreen-52 & $0.400 * / \mathbf{0 . 1 1 1} *$ & $0.455^{*} / \mathbf{0 . 2 1 8} *$ & $0.351 *$ & $0.457^{*}$ \\
\hline "Parent relations" of kidscreen-52 & $0.418 * / \mathbf{0 . 1 1 9} *$ & $0.487 * / \mathbf{0 . 2 9 6} *$ & $0.314 *$ & $0.462 *$ \\
\hline Total score of SDQ & $-0.503 * /-0.201$ & $-0.540 * /-\mathbf{0 . 2 6 8} *$ & $-0.397 *$ & $-0.542 *$ \\
\hline Maladaptive emotion regulation strategies of FEEL-KJ & $-0.360 *$ & $-0.452 * /-0.294 *$ & $-0.279 *$ & $-0.417 *$ \\
\hline Adaptive emotion regulation strategies of FEEL-KJ & $0.285^{*}$ & $0.348 * / \mathbf{0 . 1 3 6} *$ & $0.340 * / \mathbf{0 . 1 3 9} *$ & $0.374 *$ \\
\hline
\end{tabular}

Bivariate/partial correlations with validation measures of the sample at baseline $(n=459)$. Bold: partial correlations controlling for the other MHCSF-A subscales

$E W B$ emotional well-being, $P W B$ psychological well-being, $S W B$ social well-being, $M H C$-SF-A Mental Health Continuum-Short form for Adolescents, $S D Q$ The Strengths and Difficulties Questionnaire, SPPC Social Perception Profile for Children

$* p<0.01$ 
Table 9 CFA models of the latent structure of the MHC-SF-A and the SDQ

\begin{tabular}{lll}
\hline & One-factor & Two-continua model \\
\hline$\chi^{2}(\mathrm{df})$ & $78.316(9)^{*}$ & $54.470(8)^{*}$ \\
CFI & 0.913 & 0.942 \\
TLI & 0.856 & 0.891 \\
RMSEA & 0.131 & 0.114 \\
SRMR & 0.079 & 0.066 \\
AIC & 8208 & 8187 \\
BIC & 8258 & 8240 \\
\hline
\end{tabular}

$\chi^{2}$ Satorra-Bentler scaled chi-square, $d f$ degree of freedom, $C F I$ comparative-fit index, TLI Tucker-Lewis index, RMSEA root mean square error of approximation, $S R M R$ standardized root mean square residual, $C F A$ confirmatory factor analysis, $M H C-S F-A$ Mental Health Continuum-Short form for Adolescents, AIC Akaike's information criterion, BIC Bayesian information criterion

${ }^{*} p<0.01$

Asian countries (Lim 2014; Guo et al. 2015). Based on these findings and the measurement invariance of the MHCSF across cultural groups (Joshanloo et al. 2013), it can be expected that the MHC-SF could not only be used worldwide in adult samples but also in adolescent samples to measure well-being, which would enable comparisons of well-being between different cultures and different ages. Moreover, the instrument comprehensively measures wellbeing across emotional, psychological, and social domains. In accordance to other studies, the EWB, PWB, and SWB subscales were highly interrelated. This suggests that interventions that foster one dimension (e.g., EWB), may indirectly also foster the other two dimensions.

In addition to its structure, this study evaluated further psychometric properties of the MHC-SF-A. The internal consistencies of the subscales EWB, PWB were high, and for SWB adequate. The lower, but still acceptable, internal consistency of SWB was also found in other studies (Keyes et al. 2008; Lamers et al. 2011; Salama-Younes and Ismaïl 2011; Petrillo et al. 2015). Compared to the items of EWB and PWB, the items of SWB rely more on an individual's own perceptions of abstract concepts (e.g., society), which makes measuring SWB more challenging. In addition, the evaluation of the test-retest reliability suggests that the MHC-SF-A is sufficiently stable over time, but also sensitive to changes. The present study also demonstrates convergent validity of the MHC-SF-A. Measures of individual functioning such as self-esteem, showed a small partial correlation with PWB. These findings are in line with previous research (Lamers et al. 2011). The low correlation might be explained by the fact that self-acceptance, an aspect of PWB, which places emphasis on acceptance of the self and of one's past life (Ryff 1989), is not entirely representative of self-esteem which focuses on a positive self-judgement (Rosenberg 1965). Also all significant partial correlations were low. This might be due to the fact that the validation measures are only representative for an aspect of the subscales of the MHC-SF-A. In summary, the evaluation of the psychometric properties of the MHC-SF-A indicates that this measuring instrument is a reliable and valid instrument to measure well-being among Dutch adolescents.

Looking more closely at the correlations of the three subscales EWB, PWB and SWB and the other measures (i.e., positive emotions), a number of findings stood out. Measures such as positive emotions, an aspect of EWB, were not only associated with EWB but also with PWB. This finding is in line with previous research (Morrish et al. 2018). Positive emotions are important in building psychological, social and physical resources and can broaden the thought and action repertoire and promote social connections with others (Fredrickson 2001; Morrish et al. 2018). For each MHC-SF-A subscale, correlations were consistently highest with the validation measure positive emotions, suggesting that interventions aimed at fostering well-being may consider positive emotions as the primary intervention target.

Besides positive emotions, school environment appears to play an important role in adolescents' psychological life. The subscale "School environment" of the kidscreen-52 was associated with all three MHC-SF-A subscales. The way adolescents evaluate and experience their school life, has been shown to affect their EWB (Morrish et al. 2018). The subscale "School environment" partly measures feelings about school and therefore also matches EWB, which is about feelings in general. High adolescents' schoolrelated EWB has several benefits such as increased academic functioning, increased self-efficacy and better school behavior (Aldao et al. 2010). Also, being involved in school activities offers opportunities for adolescents to explore social roles and thus enhance SWB (Salama-Younes, and Ismail 2011). This might explain why the subscale School environment is additionally associated with PWB and with SWB. In summary, the way an adolescent experiences their school life has a strong influence on the adolescent's wellbeing. This underlines the importance of school-related well-being and the role that schools can play in the adolescent's global well-being. Interventions targeting wellbeing have the potential of reaching a large group of adolescents varying in background and socio-economic status in a cost-effective way. Schools can be seen as settings to promote well-being, a notion supported by the observation that measures of school environment correlate more strongly with all the well-being subscales of the MHC-SF-A than measures of social relationships.

Two main domains of social relationships that have been investigated in this study are parent-adolescent 
relationships and relationships with peers. Peer relationships play a role in the development of social skills that are necessary for personal growth and social adjustment (Greca, and Lopez 1998). This might explain why the subscale "Social Support and Peers" of the kidscreen-52 is associated with PWB. Besides relationships with peers, the quality of the parent-adolescent relationship has been measured. Although during adolescence the focus of adolescents' relationships gradually shifts from the family to peers (Brown 2004), the quality of the parent-adolescent relationship remains an important determinant of self-esteem (Arbona, and Power 2003). This might explain why the nature of the relationship with parents is associated with PWB. Apart from associations with PWB, the quality of parent relationships and relationships with peers were also linked to EWB. Positive emotions, an aspect of EWB, promote social connections with others in general (Morrish et al. 2018). Comparing to non-family factors, family factors are more important in explaining the variations in adolescents' life satisfaction and thus also in EWB (Gray et al. 2013).

Generally, a crucial skill for building and maintaining positive relationships is having adaptive emotion regulation strategies (Morrish et al. 2018). These strategies are associated with greater peer acceptance and bolster social competence (Morrish et al. 2018). This might explain the correlation of adaptive emotion regulation strategies with PWB and SWB. In contrast to adaptive emotion regulation strategies, maladaptive emotion regulation strategies only have partial correlation with PWB. Adolescents with low self-regulation, evoke negative social interaction which in turn can contribute to the development of psychopathology (Morrish et al. 2018). Various studies have confirmed the two-continua model in non-clinical populations. Evidence of the two-continua model was found in adult samples from the Netherlands, South Africa, Italy and the U.S. (Keyes et al. 2008; Lamers et al. 2011; Petrillo et al. 2015) and in U.S. adolescent samples (Keyes 2006; Greenspoon and Saklofske 2001).

The present study also confirmed the two-continua model in a Dutch adolescent sample. Well-being and mental illness are distinct indicators and have a moderately high negative correlation. This has implications for mental health interventions and treatment. The absence of psychopathology does not necessarily imply well-being. Psychological interventions for promoting well-being are useful and have an additional value to approaches that focus on treatment of mental problems. Interventions aimed at adolescents that solely focus on mental illness will not necessarily result in mentally healthier adolescents. Additionally, as well-being and mental illness are considered as continua of mental health, both measures of well-being and mental illness are needed to accurately predict therapy outcomes (de Cates et al. 2015; Thornicroft and Slade 2014). Nevertheless, it remains unclear whether the two-continua model will be confirmed in clinical populations. In clinical populations, well-being and mental illness are much more strongly entwined than in general populations (Erp Taalman and Hutschemaekers 2018).

The study has several strengths. A large research sample was recruited through secondary schools and covered different regions of the Netherlands. On top of that, the adolescents completed a large online questionnaire at baseline and at a 4-week follow-up. By doing so, the research could show prospective associations with wellbeing and other measurements of individual functioning (e.g., self-esteem). Nevertheless, the limitations of this study should be noted. First, to evaluate the psychometric properties of the MHC-SF-A self-report measures were the only form of assessment. In order to minimize the response biases, it would be useful to utilize a multi-modal approach in future research, e.g., to use observations or interviews in conjunction with self-report measures (Paulhus, and Vazire 2007). Secondly, the assessment of convergent validity of SWB is the weaker part of the study. Validated scales measuring SWB in Dutch adolescents are not yet available. The third limitation concerns the generalizability of the results. The sample of Dutch adolescents was obtained by means of convenience sampling. Although efforts were made to collect a representative sample, boys were relatively underrepresented in our study $(38.2 \%$ vs. $50 \%$ at the population level, CBS 2020). However, compared to the Dutch population (CBS 2020), the sample was representative in terms of educational level and migration background. This study possibly involved an oversampling of mentally healthy adolescents. Future studies should address whether these effects hold for adolescents who score high on psychopathology.

\section{Conclusion}

The data supported the use of MHC-SF-A in a sample of Dutch adolescents. The MHC-SF-A is a reliable and valid instrument to measure well-being among Dutch adolescents. In line with findings in other populations, mental illness and well-being also represent two related but distinct continua of mental health in Dutch adolescents. Therefore, mental health programs for adolescents should focus both on maintaining or promoting well-being in addition to the prevention of mental illness. Measures of well-being, like the MHC-SF-A, and mental illness are needed to accurately predict therapy or intervention outcomes in adolescent populations. Our findings suggest that promoting positive emotions, creating a supportive and loving parent-adolescent relationship, and a supportive 
school environment will ultimately contribute to adolescents' mental health.

\section{Compliance with Ethical Standards}

Conflict of Interest The authors declare that they have no conflict of interest.

Ethical Approval All procedures performed in studies involving human participants were in accordance with the ethical standards of the institutional and/or national research committee (include name of committee + reference number) and with the 1964 Helsinki declaration and its later amendments or comparable ethical standards.

Informed Consent At the start of the study, informed consents were obtained from adolescent participants and the parents of the adolescent participants up under 16 years old. In the informed consent, ethical and privacy issues were covered. Confidentiality as well as anonymity was ensured.

Publisher's note Springer Nature remains neutral with regard to jurisdictional claims in published maps and institutional affiliations.

Open Access This article is licensed under a Creative Commons Attribution 4.0 International License, which permits use, sharing, adaptation, distribution and reproduction in any medium or format, as long as you give appropriate credit to the original author(s) and the source, provide a link to the Creative Commons license, and indicate if changes were made. The images or other third party material in this article are included in the article's Creative Commons license, unless indicated otherwise in a credit line to the material. If material is not included in the article's Creative Commons license and your intended use is not permitted by statutory regulation or exceeds the permitted use, you will need to obtain permission directly from the copyright holder. To view a copy of this license, visit http://creativecommons. org/licenses/by/4.0/.

\section{References}

Ahern, N. R., Kiehl, E. M., Sole, M. L., \& Byers, J. (2006). A review of instruments measuring resilience. Issues in Comprehensive Pediatric Nursing, 29, 103-125.

Akaike, H. (1974). A new look at the statistical model identification. IEEE Transactions on Automatic Control, 19(6), 716-723. https://doi.org/10.1109/TAC.1974.1100705. MR 0423716.

Aldao, A., Nolen-Hoeksema, S., \& Schweizer, S. (2010). Emotionregulation strategies across psychopathology: a meta-analytic review. Clinical Psychology Review, 30(2), 217-237. https://doi. org/10.1016/j.cpr.2009.11.004.

Arbona, C., \& Power, T. G. (2003). Parental attachment, self-esteem, and antisocial behaviors among African American, European American, and Mexican American adolescents. Journal of Counseling Psychology, 50, 40-51.

Arbuckle, J.L. (2016). Amos24 User's Guide. IBM. ftp://public.dhe. ibm.com/software/analytics/spss/documentation/statistics/24.0/ en/amos/Manuals/IBM_SPSS_Amos_User_Guide.pdf.

Brown, B.B. (2004). Adolescents' relationships with peers. In R. M. Steinberg (Ed.), Handbook of adolescent psychology ( $\mathrm{pp}$. 363-394). Hoboken, NJ: Wiley.

CBS. (2020). Retrieved from jeugdmonitor. https://jeugdmonitor.cbs.nl/.

Coleman, J. C., \& Hendry, L. B. (1990). The nature of adolescence. New York: Routledge.
Colten, E., \& Gore, S. (1991). Adolescent stress:causes and consequences. New York: Hawtorne.

Cracco, E., Van Durme, K., \& Braet, C. (2015). Validation of the FEEL-KJ: an instrument to measure emotion regulation strategies in children and adolescents. PLoS ONE, 10(9), e0137080. https:// doi.org/10.1371/journal.pone.0137080.

de Cates, A., Stranges, S., Blake, A., \& Weich, S. (2015). Mental wellbeing: an important outcome for mental health services? The British Journal of Psychiatry, 207(3), 195-197.

Diener, E., Suh, E. M., Lucas, R., \& Smith, H. L. (1999). Subjective well-being: three decades of progress. Psychological Bulletin, 125(2), 276-302.

Erp Taalman, R. M., \& Hutschemaekers (2018). Health,well-being, and psychopathology in a clinical population: structure and discriminant validity of mental health continuum short form. Journal of Clinical Psychology, 74, 1719-1729. https://doi.org/10.1002/ jclp.22621.

Fredrickson, B. L. (2001). The role of positive emotions in positive psychology: the broaden-and-build theory of positive emotions. American Psychologist, 56, 218-226.

Furman, W., \& Buhrmester, D. (1992). Age and sex differences in perceptions of networks of personal relationships. Child Development, 63, 103-115.

Gloldbeck, L., Schmitz, T. G., Besier, T., Herschbach, P., \& Henrich, G. (2007). Life satisfaction decreases during adolescence. Quality of Life Research, 16, 969-979. https://doi.org/10.1007/s11136007-9205-5.

Gonzalez-Carrasco, M., Casas, F., Malo, S., Vinas, F., \& Dinisman, T. (2017). Changes with age in subjective well-being through the adolescent years: differences by gender. Journal of Happiness Studies, 18, 63-88. https://doi.org/10.1007/s10902-0169717-1.

Gray, R. S., Chamratrithirong, A., Pattaravanich, U., \& Prasartkul, P. (2013). Happiness among adolescent students in Thailand: family and non-family factors. Social Indicators Research, 10, 703-719. https://doi.org/10.1007/s11205-011-9954-y.

Greca, A. M., \& Lopez, N. (1998). Social anxiety among adolescents: linkages with peer relations and friendships. Journal of Abnormal Child Psychology, 26(2), 83-94.

Greenspoon, P. J., \& Saklofske, D. H. (2001). Toward an integration of subjective well-being and psychopathology. Social Indicators Research, 54(1), 81-108.

Guo, C., Tomson, G., Guo, J., Li, X., Keller, C., \& Söderqvist (2015). Psychometric evaluation of the Mental Health Continuum-Short Form (MHC-SF) in Chinese adolescents-a methodological study. Health and Quality of Life Outcomes, 13(1), 1. https://doi. org/10.1186/s12955-015-0394-2.

Hampel, P., \& Petermann, F. (2006). Perceived stress, coping, and adjustment in adolescents. Journal of Adolescent Health, 38(4), 409-415.

Hong Chui, W., \& Wong, M. Y. H. (2016). Gender differences in happiness and life satisfaction among adolescents in Hong Kong: relationships and self-concept. Social Indicators Research, 125, 1035-1051. https://doi.org/10.1007/s11205-015-0867-z.

Hu, L., \& Bentler, P. M. (1999). Cutoff criteriaria for fit indexes in covariance structure. Structural Equation Modeling Analysis: Conventional Criteria Versus New Alternatives, 6(1), 1-55. https://doi.org/10.1080/10705519909540118.

Hutcheson, G.D., \& Sofroniou, N. (1999). The multivariate social scientist: introductory statistics using generalized linear models. Thousand Oaks, CA: Sage Publications. https://doi.org/10.4135/ 9780857028075.

Joshanloo, M., Wissing, M. P., Khumalo, I. P., \& Lamers, S. M. (2013). Measurement invariance of the Mental Health Continuum-Short Form (MHC-SF) across three cultural groups. Personality and Individual Differences, 55(7), 755-759. 
Keyes, C. L. M. (2006). Mental health in adolescence: is America's youth flourishing? The American Journal of Orthopsychiatry, 76 (3), 395-402. https://doi.org/10.1037/0002-9432.76.3.395.

Keyes, C. L. M., \& Grzywacz, J. G. (2005). Health as a complete state: the added value in work performance andhealthcare costs. Journal of Occupational and Environmental Medicine, 47(5), 523-532. https://doi.org/10.1097/01.jom.0000161737.21198.3a.

Keyes, C. L. M., Wissing, M., Potgieter, J. P., Temane, M., Kruger, A., \& van Rooy, S. (2008). Evaluation of the Mental Health Continuum-Short Form (MHC-SF) in Setswana-speaking South Africans. Clinical Psychology \& Psychotherapy, 15(3), 181-192. https://doi.org/10.1002/cpp.572.

Keyes, C. L. (2002). The mental health continuum: from languishing to flourishing in life. Journal of Health and Social Behavior, 43 (2), 207-222.

Keyes, C. L. M. (1998). Social well-being. Social Psychological Quarterly, 61, 121-140.

Keyes, C.L.M. (2009). The nature and importance of mental health in youth. In M.F.R. Gilman (Ed.), Promoting wellness in children and youth: a handbook of positive psychology in the schools (pp. 9-23). New York: Routledge.

Kline, R. B. (1998). Principles and practice of structural equation modeling. New York: The Guilford Press.

Lamers, S. M. A., Westerhof, G. J., Bohlmeijer, E. T., ten Klooster, P. M., \& Keyes, C. L. M. (2011). Evaluating the psychometric properties of the mental health continuum-short form (MHC-SF). Journal of Clinical Psychology, 67(1), 99-110.

Larson, R., \& Ham, M. (1993). Stress and "storm and stress" in early adolescence: the relationship of negative events with dysphoric affect. Developmental Psychology, 29, 130-140.

Lim, Y. (2014). Psychometric characteristics of the korean mental health continuum-short form in an adolescent sample. Journal of Psychoeducational Assessment, 32(4), 356-346. https://doi.org/ 10.1177/0734282913511431.

Liu, W., Mei, J., Tian, L., \& Huebner, E.S. (2015). Age and gender differences in the relation between school-related social support and subjective well-being in school among students. Social Indicators Research. https://doi.org/10.1007/s11205-015-0873-1.

McGorry, P. D., Purcell, R., Hickie, I. B., \& Jorm, A. F. (2007). Investing in youth mental health is a best buy. Medical Journal of Australia, 187(7), S5-S7.

McGorry, P., \& van Os, J. (2013). Redeeming diagnosis in psychiatry: timing versus specificity. The Lancet, 381(9863), 343-345.

Morrish, L., Rickard, N., Chyuan Chin, T., \& Vella-Brodrick, D. A. (2018). Emotion regulation in adolescent well-being and positive education. Journal of Happiness Studies, 19, 1543-1564. https:// doi.org/10.1007/s10902-017-9881-y.

Muris, P., Meesters, C., \& Van Den Berg, F. (2003). The Strengths and Difficulties Questionnaire (SDQ) further; evidence for its reliability and validity in a community sample of Dutch children and adolescents. European Child \& Adolescent Psychiatry, 12(1), 1-8.

Nelson, E., Leibenluft, E., Tone, E., \& Pine, D. (2005). The social reorientation of adolescence: a neuroscience perspective. Psychological Medicine, 35, 163-174. https://doi.org/10.1017/ S0033291704003915.

Nunnally, J., \& Berstein, I. (1995). Psychometric theory. New York: Mcgraw-Hill.
Paulhus, D. L., \& Vazire, S. (2007). The self-report method. Handbook of research methods in personality psychology, 1, 224-239.

Petrillo, G., Capone, V., Caso, D., \& Keyes, C. L. M. (2015). The Mental Health Continuum-Short Form (MHC-SF) as a measure of well-being in the Italian context. Social Indicators Research, 121, 291-312. https://doi.org/10.1007/s11205-014-0629-3.

R Core Team. (2019). $R$ : a language and environment for statistical computing. Vienna, Austria. http://www.R-project.org/. R foundation for statistical computing.

Ravens-Sieberer, U., Gosch, A., Rajmil, L., Erhart, M., Bruil, J., \& Power, M. et al. (2008). KIDSCREEN-52 quality of life measure for children and adolescents: psychometric results from a crosscultural survey in 13 European countries. Value in Health, 11(4), $645-658$.

Rosenberg, M. (1965). Society and the adolescent self-image. Princeton, NJ: Princeton University Press.

Ryff, C. D. (1989). Happiness is everything, or is it? Explorations on the meaning of psychological wellbeing. Journal of Personality and Social Psychology, 57(6), 1069-1081.

Salama-Younes, M., \& Ismail, A. (2011). Validation of the factor structure of the Mental Health Continuum Short Form (MHC-SF) for physically active old out. World Journal of Sport Sciences, 4 (1), 24-30.

Sisk, C. L., \& Zehr, J. L. (2005). Pubertal hormones organize the adolescent brain and behavior. Frontiers in Neuroendocrinology, 26(3-4), 163-174. https://doi.org/10.1016/j.yfrne.2005.10.003.

Stone, M. (1979). Comments on model selection criteria of Akaike and Schwarz. (Series B). Journal of the Royal Statistical Society, 41, 276-278.

Tabachnick, B. G., \& Fidell, L. S. (2001). Using Multivariate Statistics. Boston: Allyn \& Bacon.

Thornicroft, G., \& Slade, M. (2014). New trends in assessing the outcomes of mental health interventions. World Psychiatry, 13 (2), 118-124. https://doi.org/10.1002/wps.20114.

Treffers, D. A., Goedhart, A. W., Veerman, J. W., Van den Bergh, B. R. H., Ackaert, L., \& Derycke, L. (2002). De competentiebelevingsschaal bij adolescenten (CBSA). Handleiding. Lisse: Swets \& Zeitlinger B.V.

Uusitalo-Malmivaara, L. (2014). Happiness decreases during early adolescence-a study on 12- and 15-year-old Finnish students. Psychology, 5, 541-555. https://doi.org/10.4236/psych.2014. 56064.

Waterman, A. S. (1993). Two conceptions of happiness: contrasts of personal expressiveness (eudaimonia) and hedonic enjoyment. Journal of Personality and Social Psychology, 64(4), 678-691.

Waters, L. (2011). A review of school-based positive psychology interventions. The Australian Educational and Developmental Psychologist, 28(02), 75-90.

World Medical Association. (2013). World Medical Association Declaration of Helsinki: ethical principles for medical research involving human subjects. JAMA, 310(20), 2191-2194. https:// doi.org/10.1001/jama.2013.281053.

Zimmermann, P., \& Iwanski, A. (2014). Emotion regulation from early adolescence to emerging adulthood and middle adulthood: age differences, gender differences, and emotion-specific developmental variations. International Journal of Behavioral Development, 38(2), 182-194. https://doi.org/10.1177/0165025413515405. 